Subscriber access provided by Lib4RI - Library for Eawag, Empa, PSI \& WSL

Article

\title{
Ultrathin alumina membranes as scaffold for epithelial cell culture from the intestine of rainbow trout
}

Carolin Drieschner, Matteo Minghetti, Songmei Wu, Philippe Renaud, and Kristin Schirmer

ACS Appl. Mater. Interfaces, Just Accepted Manuscript • DOI: 10.1021/acsami.7b00705 • Publication Date (Web): 28 Feb 2017

Downloaded from http://pubs.acs.org on February 28, 2017

\section{Just Accepted}

"Just Accepted" manuscripts have been peer-reviewed and accepted for publication. They are posted online prior to technical editing, formatting for publication and author proofing. The American Chemical Society provides "Just Accepted" as a free service to the research community to expedite the dissemination of scientific material as soon as possible after acceptance. "Just Accepted" manuscripts appear in full in PDF format accompanied by an HTML abstract. "Just Accepted" manuscripts have been fully peer reviewed, but should not be considered the official version of record. They are accessible to all readers and citable by the Digital Object Identifier (DOI®). "Just Accepted" is an optional service offered to authors. Therefore, the "Just Accepted" Web site may not include all articles that will be published in the journal. After a manuscript is technically edited and formatted, it will be removed from the "Just Accepted" Web site and published as an ASAP article. Note that technical editing may introduce minor changes to the manuscript text and/or graphics which could affect content, and all legal disclaimers and ethical guidelines that apply to the journal pertain. ACS cannot be held responsible for errors or consequences arising from the use of information contained in these "Just Accepted" manuscripts. 


\section{Ultrathin alumina membranes as scaffold for} epithelial cell culture from the intestine of rainbow

\section{trout}

Carolin Drieschner ${ }^{1,2}$, Matteo Minghetti ${ }^{1,3}$, Songmei $W u^{2,4}$, Philippe Renaud ${ }^{2}$, Kristin

Schirmer ${ }^{1,5,6^{*}}$

${ }^{1}$ Eawag, Swiss Federal Institute of Aquatic Science and Technology, 8600 Dübendorf, Switzerland,

${ }^{2}$ Microsystems Laboratory 4, School of Architecture, École Polytechnique Fédérale de Lausanne, 1015 Lausanne, Switzerland,

${ }^{3}$ Department of Integrative Biology, Oklahoma State University, 74078 Oklahoma, USA

${ }^{4}$ School of Science, Beijing Jiaotong University, 100044 Beijing P. R., China

${ }^{5}$ Department of Civil and Environmental Engineering, School of Architecture, École

Polytechnique Fédérale de Lausanne, 1015 Lausanne, Switzerland,

${ }^{6}$ ETH-Zürich, Institute of Biogeochemistry and Pollutant Dynamics, 8093 Zürich, Switzerland

*Corresponding author 


\section{ABSTRACT}

Permeable membranes are indispensable for in vitro epithelial barrier models. However, currently available polymer-based membranes are low in porosity and relatively thick, resulting in a limited permeability and unrealistic culture conditions. In this study, we developed an ultrathin, nanoporous alumina membrane as novel cell culture interface for vertebrate cells, with focus on the rainbow trout (Onchorynchus mykiss) intestinal cell line RTgutGC. The new type of membrane is framed in a silicon chip for physical support and has a thickness of only $1 \mu \mathrm{m}$, with a porosity of $15 \%$ and homogeneous nanopores $(\varnothing=73 \pm$ $21 \mathrm{~nm})$. Permeability rates for small molecules, namely lucifer yellow, dextran 40 and bovine serum albumin, exceeded those of standard polyethylene terephthalate (PET) membranes by up to 27 fold. With the final goal to establish a representative model of the fish intestine for environmental toxicology, we engineered a simple culture set-up, capable to test the cellular response towards chemical exposure. Herein, cells were cultured in a monolayer on the alumina membranes and formed a polarized epithelium with apical expression of the tight junction protein ZO-1 within 14 days. Impedance spectroscopy, a non-invasive and real time electrical measurement, was used to determine cellular resistance during epithelial layer formation and chemical exposure to evaluate barrier functionality. Resistance values during epithelial development revealed different stages of epithelial maturity and were comparable with the in vivo situation. During chemical exposure, cellular resistance changed immediately when barrier tightness or cell viability was affected. Thus, our study demonstrates nanoporous alumina membranes as promising novel interface for alternative in vitro approaches, capable to allow cell culture in a physiologically realistic manner and to enable high quality microscopy and sensitive measurement of cellular resistance.

\section{KEYWORDS}

fish-gut-on-chip, in vitro epithelial barrier model, ultrathin membrane, anodized aluminum, cell culture interface, impedance based toxicity testing 


\section{INTRODUCTION}

Fish play an important role in environmental toxicology to assess the risk of chemicals potentially released into the aquatic environment and to test the quality of effluent samples. ${ }^{1-2}$ Alternative approaches to reduce the number of required fish, and to prevent ethically questionable and expensive animal experimentation, include the use of primary cells and fish cell lines. ${ }^{3-5}$ Like in human toxicology, a goal is to establish realistic tissue models in order to predict organ specific interactions of hazardous substances and to understand systemic effects. ${ }^{6}$

Organ-on-chip devices play a key role in the development of novel, physiologically realistic in vitro systems. Moreover, the connection of these miniaturized organ analogues on a microfluidic platform allows to combine different cell types to a human-on-a-chip bioreactor. ${ }^{7-10}$ In our research we envision a similar development to achieve a fish-on-a-chip.

The cornerstone of each organ-on-chip device is set by microtechnological innovations. In this paper we focus on the improvement of permeable membrane systems useful for epithelial cell cultures, such as the RTgutGC cell line, established from the intestine of rainbow trout (Onchorynchus mykiss). ${ }^{11}$ With the fish intestine being a major organ for chemical absorption from the diet and partially from water ${ }^{12-13}$, an adequate in vitro system will allow to obtain insights in chemical uptake and defence mechanisms. Moreover, it will contribute to knowledge expansion for this hardly accessible organ, useful for fish physiology and aquaculture.

In vivo, epithelial cells are underlined by the delicate basement membrane, which separates them from the underlying tissue. The basement membrane is only a few hundred nanometre thick, elastic with a 3 dimensional shape and highly permeable. ${ }^{14}$ In contrast, conventionally used porous polyethylene terephthalate (PET) and polyester (PE) membranes for epithelial tissue models are stiff, several micrometre thick and low in porosity, certainly influencing cell behaviour, translocation of soluble factors, particles and chemicals. ${ }^{15-17}$ Fabrication of an ultrathin, highly permeable and formable artificial membrane was not jet demonstrated and remains a futuristic goal. Therefore, current customized membranes focus on the improvement of one or a combination of two features of natural basement membranes. For example, the first stretchable membrane, composed of polydimethylsiloxane (PDMS), was introduced by Huh et al. $2012^{18}$ and incorporated in a human-lung-on-a-chip ${ }^{18-19}$ and humangut-on-a-chip ${ }^{20-21}$ microfluidic bioreactor, allowing to simulate breathing or peristaltic 
motions. Another outstanding innovation is the development of 3-dimensional membranes made of the photoresist SU-8, with the geometry of human intestinal villi, to mimic key aspects of the intestinal epithelium. ${ }^{22}$ However, both types of membranes cannot compete with the thinness and sponginess of the natural basement membrane.

Owing to the development of advanced micro- and nanotechnologies, several ultrathin porous membranes have recently been fabricated for cell culture applications. Typically, these membranes are integrated in silicon chips due to their fabrication process and for mechanical support. Until now, membrane materials include silicon nitride $\left(\mathrm{SiN}_{\mathrm{x}}\right)$ and porous nanocrystalline silicon (pnc-Si). Experiments with pnc-Si provide information on biocompatibility and cell behaviour. ${ }^{23}$ With porous $\mathrm{SiN}_{\mathrm{x}}$ membranes, complex tissue models of brain and lung have been established. ${ }^{24-27}$

In search for novel, biocompatible materials and simple, inexpensive fabrication techniques for ultrathin membranes, we here present the development of nanoporous aluminum oxide as unique interface for epithelial intestinal cells from rainbow trout. The anodization of aluminum, resulting in a highly ordered, nanoporous structure, is a well-known, low-cost and reproducible process. ${ }^{28} \mathrm{We}$ applied this process to very thin aluminum layers, to obtain optically transparent and mechanically robust permeable membranes. The membranes are integrated in silicon chips and have a thickness of only $1 \mu \mathrm{m}$ and pore sizes in the nanometre range. A customized set-up for standard cell culture multiwell plates was designed to facilitate culturing of RTgutGC cells on chip. Microscopic monitoring of the cells reinsured the materials biocompatibility and revealed an epithelial layer formation in a physiological manner. To further validate the system, we exposed the artificial intestinal epithelium to chemicals and examined barrier integrity using cell-based impedance spectroscopy ${ }^{29}$ as noninvasive and real time monitoring tool.

\section{EXPERIMENTAL SECTION}

\section{Fabrication of nanoporous alumina membranes}

Ultrathin alumina membranes were fabricated using standard microfabrication technology. The process flow is depicted in Figure S1 (see Supporting Information). Briefly, $200 \mathrm{~nm}$ of low stress silicon nitride ( $\mathrm{SiNx}$ ) was deposited on both sides of a $380 \mu \mathrm{m}$ thick silicon wafer by low pressure chemical vapour deposition (LPCVD). The LPCVD was performed in a 
dedicated furnace, where the $\mathrm{SiNx}$ is formed by a gas flow of dichlorosilane $\left(\mathrm{SiH}_{2} \mathrm{Cl}_{2}\right)$ in presence of ammonia $\left(\mathrm{NH}_{3}\right)$, at a temperature of $820-850^{\circ} \mathrm{C}$. Photolithography and reactive ion etching (RIE) were used to pattern free-standing silicon nitride membrane arrays. Therefore, $300 \mu \mathrm{m}$ of silicon were etched vertically with RIE from the wafers backside, followed by pyramidal chemical etching in potassium hydroxide $(\mathrm{KOH})$ solution, to release free-standing SiNx membranes with a final size of $800 \mu \mathrm{m}$ x $800 \mu \mathrm{m}$. SiNx membranes serve as supportive layer for future alumina membranes. Next, a $1 \mu \mathrm{m}$ layer of aluminum (Al) was deposited on the SiNx film on the wafer's front side and then anodized in $6 \mathrm{wt} \%$ phosphoric acid by applying $100 \mathrm{~V}$. To subsequently remove phosphoric acid residue, the anodized wafer was rinsed extensively with deionized water and dried under laminar flow. Finally, nanoporous alumina membranes were released by selective dry etching of the $\mathrm{SiNx}$ supportive layer from the wafers backside. Individual Si-chips of $9 \mathrm{~mm}$ x $9 \mathrm{~mm}$ were obtained upon manual cleavage along cleavage lines. Each chip is composed of a micro-well array of 21 equal sized nanoporous alumina membranes $(800 \mu \mathrm{m} \times 800 \mu \mathrm{m})$, with a total membrane area of $13.44 \mathrm{~mm}^{2}$.

For membrane inspection and pore size analysis, scanning electron microscopy (SEM) images were taken randomly from independent anodization bates, using a Zeiss LEO 1550 scanning electron microscope. In addition, spatial inspection of pose size (center, top-, bottom-, rightand left corner) of the anodized wafer surface revealed no significant spatial pore size variation. The pore size and density was analyzed with a MATLAB script ("pore-analyzer"), kindly provided by Stefano Varricchio from microsystems laboratory 4 (LMIS4) at EPFL, Lausanne, Switzerland.

\section{Experimental setup and chip preparation}

Specifically designed plastic holders, made from $1 \mathrm{~mm}$ thick polymethyl methacrylate (PMMA) sheets (Jauslin Plexacryl sa, Switzerland), allowed the use of nanoporous alumina supports in standard 24-well cell culture plates (Greiner-bio-one, Germany) and ensured media availability from both membrane sides. In the following, this system is referred to as one-compartment system. It was used for cell culture establishment on alumina membranes and impedance based resistance measurement of the epithelial cell layer. In addition, a second set-up was developed to perform permeability experiments in absence of cells for membrane characterization. For this set-up, Si-chips were glued (Loctite M-121HP Hysol Medical Device Epoxy Adhesive, Henkel, USA) to commercial inserts (ThinCert ${ }^{\mathrm{TM}}$ for 24 well plates, Greiner-bio-one, Germany) after PET membrane removal and placed in 24-well cell culture 
plates. This set-up creates an upper (apical) and lower (basolateral) compartment which are separated by the alumina membrane, creating a two-compartment system. Prior to usage, Sichips, plastic holders and modified inserts were sterilized by incubation in $70^{\circ} \mathrm{EtOH}$ for 20 min and subsequent drying under a sterile bench.

\section{Permeability assay}

Membrane permeability of cell-free nanoporous alumina membranes was assessed in the twocompartment system and compared to permeability of PET membranes (pore size $=0.4 \mu \mathrm{m}$; pore density $=1 \times 10^{6}$ pores $/ \mathrm{cm}^{2}$ ), which are integrated in the commercial insert system (ThinCert $^{\mathrm{TM}}$ for 24 well plates, Greiner-bio-one, Germany). Two fluorescent dyes and one protein with different molecular sizes were used: lucifer yellow (LY, molecular weight = 444.25 g/mol; Molecular Probes, Netherlands), dextran FD40 (FD40, molecular weight = 40000 g/mol; Sigma Alrich, Switzerland) and bovine serum albumin (BSA, molecular weight $=66000 \mathrm{~g} / \mathrm{mol}$; Sigma Alrich, Switzerland). Dyes or protein were dissolved in PBS to a final concentration of $50 \mu \mathrm{g} / \mathrm{mL}$ for $\mathrm{LY}, 1 \mathrm{mg} / \mathrm{mL}$ for FD40 and $200 \mu \mathrm{g} / \mathrm{mL}$ for BSA. Prior to experimentation, the chambers were filled with phosphate buffered saline (PBS) and incubated for two hours at $19^{\circ} \mathrm{C}$. Working volumes were $400 \mu \mathrm{L}$ for the apical chamber and $1.4 \mathrm{~mL}$ for the basolateral chamber. Thereafter, the apical (= donor) chamber was exchanged with the same volume of the previously prepared LY-, FD40- or BSA solutions and incubated for up to 24 hours at $19^{\circ} \mathrm{C}$. For the fluorescent dyes LY and FD40, samples of $2 \times 10 \mu \mathrm{L}$ were withdrawn from the basolateral (= receiver) chamber after carful mixing at different time points during the 24 hours of the experiment. The aliquots were transferred to a 384 well plate (Greiner-bio-one, Germany) and the fluorescence was detected immediately using a multiwell plate reader (Tecan, Infinite M200, Switzerland) at the respective excitation and emission wavelengths $\left(\mathrm{LY}_{\text {excitation/emission }}=450 / 520 \mathrm{~nm}, \mathrm{FD} 40\right.$ excitation/emission $\left.=485 / 544 \mathrm{~nm}\right)$. After 24 hours (= end of experiment), a sample from the apical compartment was taken to verify the stability of the dye concentration in the apical compartment. The fluorescence data for LY, FD40 were transformed to the amount of permeated dye, based on appropriate standard curves. For BSA, $200 \mu \mathrm{L}$ samples were only taken at the end of the experiment (24 hours) from the apical and basolateral chamber and protein content was analyzed by performing the modified Lowry protein assay (Thermo Scientific, Switzerland). The apparent permeability Papp (cm/s) was calculated according to Hubatsch et al. $2007^{30}$ as follows:

$$
P_{a p p}\left[\frac{c m}{s}\right]=\frac{d Q}{d t} * \frac{1}{A * C_{0}}
$$


With $\frac{d Q}{d t}$ being the steady-state flux, A being the surface area of the membrane in $\mathrm{cm}^{2}$ and $\mathrm{C}_{0}$ being the initial concentration in the donor compartment.

\section{Cell culture}

All experiments were performed with rainbow trout intestinal cells, RTgutGC. ${ }^{11}$ For routine culture, RTgutGC cells were grown in complete medium (L-15/FBS), composed of Leibovitz L-15 medium (Invitrogen, Switzerland), supplemented with 5\% fetal bovine serum (PAA; Switzerland) and 1\% penicillin/streptomycin (GIBCO, Invitrogen, Switzerland). Cells were maintained at $19^{\circ} \mathrm{C}$ in the dark under normal atmosphere and culture medium was renewed once per week. Cells were split every one to two weeks, when reaching confluency of 80$90 \%$, with trypsin (Sigma Aldrich, Switzerland) and sub-cultured in a 1:3 ratio in $75 \mathrm{~cm}^{2}$ cell culture flasks (TPP, Switzerland). For experimentation, RTgutGC cells were grown on nanoporous alumina supports, which were integrated in a 24 well-plate on simple plastic holders (see above). For comparison, PET membranes, incorporated in commercially available transwell inserts (ThinCert ${ }^{\mathrm{TM}}, 24$-well, pore size $0.4 \mu \mathrm{m}$, transparent; Greiner-bioone, Germany), were used to represent a commonly used permeable cell culture interface. ${ }^{16}$ If not specified, the same protocols were applied to both, alumina and PET membranes. Prior to seeding, alumina and PET membranes were coated with $50 \mu \mathrm{g} / \mu \mathrm{L}$ fibronectin (Roche, Germany) in PBS for two hours. Cells were seeded in L-15/FBS either at a low density of 20000 cells $/ \mathrm{cm}^{2}$ for individual cell observation or at a high density of $55000 \mathrm{cells} / \mathrm{cm}^{2}$ for confluent cell layer formation. Two hours after cell seeding, media was changed to remove unattached cells in PET inserts. For alumina supports, the Si-chips were shortly washed in L15/FBS and placed in a new well on top of the chip holder in fresh medium. Working volumes of cell culture medium were $1 \mathrm{~mL}$ for Si-chips on plastic holders, while transwell inserts were filled apically with $400 \mu \mathrm{L}$ and basolaterally with $1.4 \mathrm{~mL}$. Cells were cultured for up to 28 days at $19^{\circ} \mathrm{C}$ and under normal atmosphere, with a media change every seven days.

\section{Scanning electron microscopy}

Two preparation techniques were performed to obtain SEM images from the cell-alumina membrane interaction. For top-view images, RTgutGC cells were cultured on alumina membranes for 24 hours. Thereafter, cells were washed with PBS and fixed in $2.5 \%$ glutardialdehyde for one hour, followed by postfixation in $2 \%$ osmium tetroxide for one hour and block staining with $2 \%$ uranyl acetate for one hour with washing steps in between. Dehydration was performed in a graded series of 30,50, 70, 90, and 100\% ethanol, followed 
by twice water-free $100 \%$ ethanol, 30 min each. Then, alumina supports with cells were plunged into liquid nitrogen followed by freeze drying at $-110^{\circ} \mathrm{C},-100^{\circ} \mathrm{C},-80^{\circ} \mathrm{C},-70^{\circ} \mathrm{C}$ and $+20^{\circ} \mathrm{C}$ for 30 min each step. The alumina supports with the dried cells were mounted on SEM aluminum stubs and sputter-coated with $5 \mathrm{~nm}$ of platinum. SEM images were recorded at 5 kV with a Zeiss Gemini 1530 FEG (Zeiss, Germany). For cross-section images, RTgutGC cells were cultured for two weeks on alumina supports. Sample preparation for fixation followed the same protocol as described for top-view images. After dehydration in increasing concentrations of ethanol, the alumina membrane with cells was impregnated first with $33 \%$ resin (EMbed 812, Electron Microscopy Science, USA) and then with 66\% resin in water-free ethanol for one hour 30 min each. Thereafter, alumina support with cells was submerged in $100 \%$ resin twice for two hours each. All impregnation steps were performed at room temperature in small plastic dishes. The sample was completely submerged in the resin and then taken out of the resin bath. Excesses of resin was allowed to drain in an upright position for another one hour $30 \mathrm{~min}$ at room temperature. The sample was then transferred to the oven to be heated up slowly to $60{ }^{\circ} \mathrm{C}$. Polymerization is allowed to take place for two days at 60 ${ }^{\circ} \mathrm{C}$. The polymerized alumina support with cells was cooled to room temperature and directly mounted right-side-up onto SEM stubs with conductive carbon cement. The specimen was sputter coated with $6 \mathrm{~nm}$ platinum. In the focused ion beam (FIB)-SEM (FEI Helios 600i), the sample was screened with an electron beam at high accelerating voltage $(30 \mathrm{kV})$ and imaged in the backscattered electron (BSE)-mode to select a region of interest. The sample was brought to a stage position, where electron beam and ion beam coincide (stage tilt at $52^{\circ}$ ) and a trench was milled with the FIB at $30 \mathrm{kV}$ and $9.3 \mathrm{nA}$ to open the sample. The resulting cross section was polished at an ion current of 2,5 nA and then imaged with an electron beam of 2 $\mathrm{kV}$ and 0,34 $\mathrm{nA}$. Images were acquired in the BSE-mode at appropriate tilt correction and a dwell time of $30 \mu \mathrm{s}$. Neighbouring images were merged to full panorama views.

\section{Light microscopy}

Images were taken on a Nikon TMS inverted microscope with a Nikon Coolpix P6000 digital camera.

\section{Fluorescence microscopy}

For immunohistochemical staining, cells were fixed with 3.7\% paraformaldehyde (Invitrogen, Switzerland) in PBS for $10 \mathrm{~min}$ at room temperature. After washing in PBS, cells were permeabilized for 15 min with $0.2 \%$ Triton X-100 in PBS. After a further washing step with 
PBS containing $0.1 \%$ Triton X-100, cells were incubated in Image-iT (Invitrogen, Switzerland) for $30 \mathrm{~min}$, rinsed with PBS and primary antibody for tight junction staining (Alexa Fluor-coupled ZO-1 antibody, Invitrogen, Switzerland) was applied overnight at $4^{\circ} \mathrm{C}$ at a concentration of $5 \mu \mathrm{g} / \mathrm{ml}$ in $0.5 \%$ goat serum and $0.05 \%$ Triton X-100 in PBS. The next day, cells were washed with $0.1 \%$ Triton X-100 in PBS. For f-actin staining, cells were incubated with FITC coupled phalloidin (1:100; Sigma-Aldrich, Switzerland) for one hour at room temperature. Subsequently, after washing in $0.1 \%$ Triton X-100 in PBS, samples were incubated with $10.9 \mu \mathrm{M}$ DAPI (Invitrogen, Switzerland) in PBS for $5 \mathrm{~min}$. After repeated washing in $0.1 \%$ Triton X-100 in PBS and PBS only, Si-chips were mounted on microscope slides using ProLong ${ }^{\circledR}$ Gold antifade reagent (Life Technology, United States) and analysed on a Leica SP5 Laser Scanning Confocal Microscope (Leica, Switzerland).

\section{Impedance spectroscopy}

Alumina membrane holding Si-chips and PET transwell inserts were placed in an Endohm-6chamber (World Precision Instruments, Germany), which was connected to an impedance analyzer (Gamry Instruments, Germany). For Si-chips, a specific holder was designed to avoid direct contact of the chip with the basolateral electrode and to limit the sensing area to the region where cells were cultured on alumina membranes. This set-up resulted in $20 \%$ leakage of the electrical current. Impedance spectra were recorded from 1 to $300000 \mathrm{~Hz}$ at an amplitude of $20 \mathrm{mV}$, with highest sensitivity at $1500 \mathrm{~Hz}$ (see Supporting Information, Figure $\mathrm{S} 2)$.

\section{Chemical exposure of epithelial cells}

As proof of concept for the sensitivity of impedance measurements through alumina membranes, we performed two chemical exposure scenarios with RTgutGC formed epithelia. First, a short-term exposure of a barrier disrupting chemical and subsequent recovery was analysed. Second, cells were continuously exposed to a barrier destructing chemical and monitored for 24 hours. Therefore, RTgutGC cells were cultured on nanoporous alumina supports until they reached impedance values of 60-70 ohms at $1500 \mathrm{~Hz}$ (minimum 14 days), as a qualify measure for barrier maturity. Prior to chemical treatment, cells were preequilibrated in L-15/ex for $30 \mathrm{~min}$. L-15/ex is a simple buffer, preferably used for chemical exposure scenarios in fish cell lines. ${ }^{31-32}$ A schematic overview about the preparation of L15/ex has been shown elsewhere. ${ }^{33}$ For the short-term exposure scenario, cells were treated for $5 \mathrm{~min}$ with $0.2 \mathrm{~g} / \mathrm{L}$ ethylenediaminetetraacetic acid (EDTA, Sigma-Aldrich, Switzerland), 
known to effect tight junction tightness by sequestering $\mathrm{Ca}^{2+}$ via chelation. Thereafter, exposure medium was exchanged with L-15/ex to allow recovery. For the continuous exposure scenario, cells were treated with $20 \mathrm{mg} / \mathrm{L}$ sodium dodecyl sulphate (SDS, SigmaAldrich, Switzerland), an anionic surfactant used in many cleaning and hygiene products.

\section{Atomic layer deposition of titanium}

We deposited a thin film of titanium on the Si-chips to prevent aluminum release from membranes. During the atomic layer deposition process, $\mathrm{TiCl}_{4}$ (precursor of $\mathrm{TiO}_{2}$ ) and $\mathrm{H}_{2} \mathrm{O}$ were sequentially exposed as vapour at $200^{\circ} \mathrm{C}$; a final thickness of 2,5 or $7 \mathrm{~nm}$ of $\mathrm{TiO}_{2}$ on the whole surface of the alumina membrane was obtained.

\section{Metal analysis}

For determination of aluminum and titanium release from alumina and titanium coated (2, 5, or $7 \mathrm{~nm}$ ) alumina membranes, we incubated the appropriate Si-chips in $1 \mathrm{~mL} \mathrm{L-15/FBS}$ in the one-compartment system for seven days. Thereafter, medium was collected and diluted 1:10 in deionized water for high resolution inductively coupled plasma mass spectrometry (HR ICP MS, Element2, Thermo, Switzerland). The total aluminum mass was measured using isotope ${ }^{27} \mathrm{Al}$. The total titanium mass was measured using isotope ${ }^{47} \mathrm{Ti}$ and ${ }^{49} \mathrm{Ti}$, due to calcium interference with the more sensitive and otherwise preferred isotope ${ }^{48} \mathrm{Ti}$. To control the reliability of quantification, water references (PlasmaCal 33 MS, SCP, Courtaboeuf, France) with a known aluminum and titanium content were measured. Aluminum speciation in L-15 medium was performed with visual MINTEQ version 3.0.

\section{RESULTS AND DISCUSSION}

The vast majority of current in vitro epithelial cell models relies on commercially available two-compartment insert systems, where epithelial cells are cultured on a polymer-based permeable membrane, dividing the system into an upper and a lower chamber. However, these membranes are several micrometre thick and often low in porosity. This almost certainly limits the translocation of molecules through the barrier system, affects epithelial architecture, influences microscopic imaging and restricts sensitive measurement of, e.g., changes in cellular resistance by transepithelial electrical resistance (TEER) or impedance monitoring. 
Ultrathin, nanoporous alumina membranes were developed with the aim to improve current epithelial barrier models, like that of the fish intestinal epithelium. The $1 \mu \mathrm{m}$ thick, transparent membranes are surrounded by a Si-chip for mechanical support (size: $9 \mathrm{~mm} \times 9$ $\mathrm{mm}$ ) and arranged as array of 21 centred squares (Figure 1A). Each membrane is $0.8 \mathrm{~mm} \mathrm{x}$ $0.8 \mathrm{~mm}$, yielding a total membrane area of $13.44 \mathrm{~mm}^{2}$. The silicon chip has a total thickness of $380 \mu \mathrm{m}$. The membrane holding side (top side) is flat, while the bottom side is characterised by 21 micro wells, which were formed during the silicon etching process and terminate into the 21 free-standing membranes. For simple and reproducible cell culture application, the Si-chip is places on top of specially designed plastic holders. These holders are compatible with common 24-well cell culture plates and allow for media availability from both sides of the alumina membranes (Figure 1B). In this way, a one-compartment system is created, allowing to follow cell growth and epithelial barrier formation by microscopy and impedance spectroscopy. In addition, we generated a two-compartment system to perform permeability studies. For this purpose, the chip is attached to commercial insert holders (Figure 1C) and placed in 24-well cell culture plates. For future applications, the chip could also be integrated in a different insert concept, which makes use e.g. of a clamping mechanism to facilitate mounting and unmounting of the chip. ${ }^{25}$ Moreover, chip design and membrane shape is flexible, and could be adapted for organ-on-chip applications. For example, a single elongated alumina membrane could build the permeable interface between an upper and a lower microfluidic channel within a PDMS based bioreactor.

The fabricated alumina membranes are characterized by densely packed nanopores, which span straight through the aluminium layer. Pore diameters range from $10-140 \mathrm{~nm}$ for the top (Figure 2A) and bottom (Figure 2B) side of the membrane. The mean diameter for the top side of the membrane is slightly bigger $(82 \pm 26 \mathrm{~nm})$ compared to the bottom side $(73 \pm 21$ $\mathrm{nm}$ ). Moreover, marginally more pores were counted on the top side (top: $43 \pm 2 \mathrm{pores} / \mu \mathrm{m}^{2}$; bottom: $36 \pm 1$ pores $/ \mu \mathrm{m}^{2}$ ). This phenomenon is attributed to the anodization process, which creates the typical, highly-ordered nanoporous structure into the aluminum layer. During anodization, pores are propagated from the top to the bottom side. ${ }^{28}$ For anodization of thin films of aluminum, it was observed that pore channels frequently evolve a branched shape and that not all initiated pores finally reach the bottom. ${ }^{34}$ According to these findings, a corresponding membrane porosity of $15 \%$ was calculated, based on bottom results. Compared to other fabrication techniques for ultrathin membranes, the anodization of thin aluminum films represents a fast and cost-efficient option to obtain a nanoporous material. ${ }^{28}$ This is different from crafting of SiNx thin films with photolithography techniques, which rather 
yield microporous membranes with pore sizes starting from $1 \mu \mathrm{m}$ upward. ${ }^{24-25}$ On the other hand, fabrication of SiNx membranes with nanopores relies on time consuming and cost intensive techniques like e-beam lithography. ${ }^{35}$ The choice of nanoporous or microporous membranes is strongly dependent on the final application and has to be considered in advance to experimentation.

Permeability of nanoporous alumina was evaluated in the two compartment insert system in absence of cells and compared to that of PET membranes (Figure 3A). The absolute amount of permeated dye (lucifer yellow or dextran FD40) or protein (bovine serum albumin) from the apical to the basolateral chamber was evaluated over 24 hours and showed faster rates for the alumina membrane (Figure 3B). For lucifer yellow, the smallest molecule analysed, an $\mathrm{P}_{\text {app }}($ alumina $)=6.2 * 10^{-5} \mathrm{~cm} / \mathrm{s}$ and $\mathrm{P}_{\text {app }}(\mathrm{PET})=7.5^{*} 10^{-6} \mathrm{~cm} / \mathrm{s}$ was calculated. For dextran FD40 we obtained the following values: $\mathrm{P}_{\text {app }}$ (alumina) $=2.3 * 10^{-5} \mathrm{~cm} / \mathrm{s}$ and $\mathrm{P}_{\text {app }}($ PET $)$ $=8.5^{*} 10^{-7} \mathrm{~cm} / \mathrm{s}$. These values correspond to the linear section of the kinetic curves recorded for both dyes (see Supporting Information, Figure S3); the calculation incorporates membrane area, whereby permeable alumina membrane area is about half the size of PET membrane area. For bovine serum albumin, we estimated $\mathrm{P}_{\text {app }}($ alumina $)=1.7 * 10^{-5} \mathrm{~cm} / \mathrm{s}$ and $\mathrm{P}_{\text {app }}(\mathrm{PET})$ $=3.2 * 10^{-6} \mathrm{~cm} / \mathrm{s}$ from the 24 hour time point. The $\mathrm{P}_{\text {app }}$ values for alumina membranes clearly show that membrane permeability decreases with molecule size, but is still much faster compared to PET membranes. These findings underline the great potential of alumina membranes in improving current in vitro epithelial barrier models for transport or co-culture studies, where the mechanical cell support is not supposed to act as barrier itself. At this point we would also like to add that alumina membranes are not suitable for nanoparticle transport studies. This type of research obviously requires bigger pore sizes, which are above the diameter of nanoparticles or nanoparticle agglomerates. ${ }^{15}$

With regard to their application as culture interface for epithelial fish cells, alumina membranes were used to investigate the interaction of RTgutGC cells with the nanoporous surface. As shown by SEM investigations after one day of culture (Figure 4A), cells are adherent to the substrate and exhibit a normal, flattened morphology. On the membrane, each cell is in contact with abundant, homogeneously distributed pores ( $\sim 36000$ pores/cell). Due to the small pore diameter, cells do not penetrate into the pores with their membrane protrusions (filopodia). Filopodia pore penetration has been observed for pore diameters of $240 \mathrm{~nm}$ and bigger. ${ }^{15,36}$ A cross-section TEM image of RTgutGC cells cultured for two weeks on alumina membranes (Figure 4B) provides an impression of the ratio between epithelial layer thickness 
and permeable support, which is around 5:1. In addition, the magnified detail of the membrane highlights the straight pores, spanning through the aluminum layer and connecting the apically located cells with the basolateral media supply. These findings make the alumina membrane a physiologically realistic support for epithelial barrier systems, such as the fish intestine.

Alumina membranes are optically transparent, allowing for routine monitoring of cell growth and morphology by light microscopy. As depicted in Figure 5A, the cells show excellent cellgrowth behaviour on the membrane. Cells attach within two hours after seeding and start to spread. Already after one day of culture, cells form a confluent monolayer when seeded at a high density of 55000 cells $/ \mathrm{cm}^{2}$. During the next 14 to 28 days, cells proliferate and become smaller and more homogeneous in size and morphology. Cellular polarization, which is a key feature of epithelial cells, was demonstrated by immunofluorescent imaging of cells stained against tight junction protein ZO-1, cytoskeleton (f-actin) and nuclei (DAPI) (Figure 5B). At day one, cells showed a highly flattened morphology with actin stress fibres and weak tight junctions on the same optical plane. During a culture period of 14 days, tight junctions continuously move toward the apical cell boarder and staining intensity becomes stronger, while actin stress fibres remain located basolaterally. Cross-section analysis (z-stack assembly) revealed that long culture periods, i.e., $\geq 4$ weeks, resulted in undesired multilayer formation on the alumina supports due to continued cell proliferation. Thus, we conclude that RTgutGC cells form a mature epithelium, which is ready for experimentation within 14 days of culture. This is slightly faster than maturation reported for the RTgutGC epithelium on the commercial PET membranes. ${ }^{16}$ In addition, we could show that alumina membranes are suitable for confocal imaging through the ultrathin membrane (cells cultured on bottom side) with the same quality (see Supporting Information, Figure S4). This can be beneficial for imaging of co-cultured cells. Next, cell-based impedance spectroscopy was assessed to allow non-invasive monitoring of epithelial barrier formation over time (Figure 5C). Therefore, cellular impedance of RTgutGC was measured every 3-4 days over the culture period of 28 days. During the first 24 hours, impedance values strongly increased to $16 \mathrm{ohms} * \mathrm{~cm}^{2}$, due to cell attachment. Thereafter, values increased steadily to $26 \mathrm{ohms}^{*} \mathrm{~cm}^{2}$ at day 28 . These results are in accordance with transepithelial electrical resistance (TEER) measurements reported for RTgutGC cells cultured in commercial transwell inserts. ${ }^{15,16}$ In addition, resistance values agree with the leaky nature of the fish intestinal epithelium in vivo ${ }^{37}$ and are thus quite different from the epithelial resistance of the frequently used human intestinal cell line Caco2, where TEER values range from $500-1000 \mathrm{ohms} * \mathrm{~cm}^{2} .{ }^{38}$ Low epithelial resistance can have 
a strong influence on measure accuracy. For RTgutGC cells cultured on PET membranes, we observed high variation among replicates (see Supporting Information, Figure S5), in agreement with previous reports where chop-stick electrodes were used. ${ }^{15,} 16$ Alumina supports, in contrast, exhibit much lower background values due their thinness and high porosity, and thus offer low set-up related variation among samples, improving measure accuracy substantially (Figure 5C). Finally, impedance values were compared with microscopical findings and additionally normalized to the resistance of day 14, where cells formed a mature epithelium (Figure 5D). According to this evaluation, the epithelial barrier formation of RTgutGC cells can be divided in 4 stages: 1) cell attachment; 2) cell spreading and formation of a confluent monolayer; 3) polarization and 4) further proliferation and multilayer formation.

Hazardous substances, taken up into the fish intestine, e.g., via diet, may influence the epithelium's role in acting as selective barrier towards food, pathogens and other toxins. We used impedance spectroscopy to monitor the RTgutGC epithelial resistance, while performing two chemical exposure scenarios. First, a short-term exposure of a barrier disrupting chemical, namely EDTA, was carried out and subsequent recovery was monitored (Figure 6A). The cellular resistance rapidly declines during the exposure period, with normalized resistance values (normalized to control) dropping rapidly from $100 \%$ to $60 \%$. Transfer of the epithelium to chemical-free medium resulted in total recovery of $100 \%$ within $50 \mathrm{~min}$. For the second exposure scenario, cells were continuously exposed to the barrier destructing chemical SDS, and monitored for 24 hours (Figure 6B, left graph). Normalized resistance values showed the greatest changes within the first four hours, where values dropped from $100 \%$ to $60 \%$. Thereafter, normalized values declined gradually to $44 \%$. Control and SDS exposed cells were stained after the 24 hours treatment, confirming a changed morphology of the actin cytoskeleton for exposed cells, which is likely induced by cellular apoptosis (Figure 6B, right images). Impedance spectroscopy was shown previously to be a suitable sensing method for water quality analysis by using the rainbow trout gill cell line, RTgill-W1, cultured directly on electrodes. ${ }^{29}$ With the conducted experiments, we demonstrate the applicability of the method for the RTgutGC epithelial barrier system, where measurement is conducted through the alumina membrane.

Alumina $\left(\mathrm{Al}_{2} \mathrm{O}_{3}\right)$ is the oxidized form of aluminum, which is formed during the anodization process. We tested the release of aluminum ions from alumina membranes into fetal bovine serum containing cell culture medium, to verify unbiased usage of this metal surface for cell 
culture applications and toxicological studies. However, we found $717 \mu \mathrm{g} / \mathrm{L}$ of aluminum released from a single Si-chip into $1 \mathrm{~mL}$ of cell culture medium during an incubation time of 7 days (Figure 7A). Using visual MINTEQ we predicted aluminum to be present in the form of aluminum hydroxide ( $\sim 90 \%)$ or bound to Glutamate \& Glycine $(\sim 10 \%)$. In general, aluminum is classified as non-priority pollutant (US EPA) due to its low toxicological impact found in humans, mammals, in vitro cell cultures and bacteria. ${ }^{39}$ For fish, aluminum can be extremely toxic when exposed under acidic $(\mathrm{pH}<6)$ or alkaline conditions $(\mathrm{pH}>8)$, by impairing the ion regulation of the gills, leading to a respiratory dysfunction. ${ }^{40}$ From these findings we conclude that alumina membranes can be used as cell culture interface without influencing cell viability and vitality, but care should be taken if $\mathrm{pH}$ shifts are to be expected. In addition, the released aluminum may interfere with metal exposure experiments, which are of interest in environmental toxicology. 5,41 Thus, in order to prevent aluminum release from the membranes, we tested a surface modification by depositing a thin film of $\mathrm{TiO}_{2}$ with atomic layer deposition (ALD) on the total membrane surface. A deposition of $2 \mathrm{~nm} \mathrm{TiO}_{2}$ decreased the aluminum release to $89 \mu \mathrm{g} / \mathrm{L}$. For 5 and $7 \mathrm{~nm} \mathrm{TiO}$ films, the Al release was below $5 \mu \mathrm{g} / \mathrm{L}$ (Figure 7A). The ALD surface modification results in smaller pore sizes according to layer thickness, which might affect permeability. However, for frequently studies molecules, such as lucifer yellow, dextran 40 or bovine serum albumin, with diameters $\leq 4 \mathrm{~nm}$, we would not expect a significant change in permeability due to the stable, high pore density. Figure $7 \mathrm{~B}$ demonstrates membrane morphology before and after ALD with $5 \mathrm{~nm} \mathrm{TiO}_{2}$. Release of titanium was not observed.

\section{CONCLUSION}

We developed a novel type of ultrathin alumina-based membrane to serve as permeable support for an in vitro tissue model, focussing on the fish intestine. Due to their unique nanoporous structure, the new membrane was found to overcome some issues of current polymer-based membranes, which are part of commercial transwell inserts. Unlike their commercial counterpart, alumina membranes closely mimic features of the basement membrane in terms of thinness, porosity and permeability. The established piscine intestinal barrier model, based on RTgutGC cell culture on alumina supports, has proved epithelial characteristics, such as the formation of a confluent polarized cell-monolayer. In future studies, it might be interesting to include a second cell type in the system. This could be a fibroblast or endothelial cell line grown on the opposite membrane side in order to mimic the 
physiological complexity of the intestinal barrier. In addition, the alumina supports could be adapted for microfluidic bioreactors, which would allow mechanical stimulation of intestinal cells as found in vivo. For optimal analysis of epithelial barrier function, we introduced cellbased impedance spectroscopy to measure changes in cellular resistance upon chemical exposure in real time. This bio-sensing method, in combination with alumina membranes, was found to be a sensitive endpoint for the in vitro piscine intestinal barrier, which naturally has a low resistance and therefore ideally mimics the leaky nature of the fish intestine. A limitation of alumina membranes can be seen in its release of aluminum ions. The released concentrations had no effect on cell growth or cellular behaviour, but might interfere with metal exposure or other types of experiments. A solution to the problem was found by a surface modification with titanium dioxide, which drastically decreased the undesired release. Overall, we developed a novel and innovative culture system for barrier forming epithelial cells, which is applicable for physiological-, permeation- and toxicological studies, and not restricted to the RTgutGC cell line. 


\section{ASSOCIATED CONTENT}

\section{Supporting Information}

The supporting information is available free of charge on the ACS Publications website at DOI:...

Fabrication process of alumina supports, impedance frequency scan, permeability kinetics of fluorescent dyes, confocal microscopy through membrane, measure accuracy in transwell inserts

\section{AUTHOR INFORMATION}

\section{Corresponding Authors}

E-mail: kristin.schirmer@,eawag.ch

Notes

The authors declare no competing financial interest.

\section{ACKNOWLEDGMENTS}

This work was funded by the Swiss National Science Foundation, grant no. CR23I2_144289. The authors would like to thank Dr. Anne Greet Bittermann and Stephan Handschin (Scientific Center for Optical and Electron Microscopy, ETH Zurich, Switzerland) for TEM and SEM analysis, Robert Meissner (Microsystems Laboratory 4, EPFL Lausanne, Switzerland) for his advice and technical discussions, Stephano Varricchio (Microsystems Laboratory 4, EPFL Lausanne, Switzerland) for providing the Matlab program "pore analyser" and David Kistler (Department of Environmental Toxicology, Eawag, Dübendorf, Switzerland) for ICP-MS measurements. 


\section{REFERENCES}

1. Leeuwen, C. J. v., Risk Assessment of Chemicals. 2nd ed.; Springer: Bilthoven, Netherlands, 2007, 290-312.

2. Dempsey, N. Animal Experiment Statistics; http://researchbriefings.parliament.uk, 18 January 2016, 1-23.

3. Bols, N. C.; Dayeh, V. R.; Lee, L. E. J.; Schirmer, K. Use of Fish Cell Lines in the Toxicology and Ecotoxicology of Fish. Piscine Cell Lines in Environmental Toxicology. In Biochemistry and Molecular Biology of Fishes, 1st ed.; Elsivier: 2005, Chapter 2, 43-85.

4. Schirmer, K. Proposal to Improve Vertebrate Cell Cultures to Establish them as Substitutes for the Regulatory Testing of Chemicals and Effluents using Fish. Toxicology 2006, 224 (3), 163-183.

5. Minghetti, M.; Schnell, S.; Chadwick, M. A.; Hogstrand, C.; Bury, N. R. A Primary Flsh Gill Cell System (FIGCS) for Environmental Monitoring of River Waters. Aquat. Toxicol. 2014, 154, 184-192.

6. Marx, U. Trends in Cell Culture Technology. Adv Exp Med Biol 2012, 745, 26-46.

7. van der Meer, A. D.; van den Berg, A. Organs-on-chips: Breaking the In Vitro Impasse. Integrat. Biol.: Quantitative Biosciences from Nano to Macro 2012, 4 (5), 461-70.

8. Esch, M. B.; King, T. L.; Shuler, M. L. The Role of Body-on-a-Chip Devices in Drug and Toxicity Studies. Ann. Rev. Biomed. Eng. 2011, 13, 55-72.

9. Huh, D.; Torisawa, Y. S.; Hamilton, G. A.; Kim, H. J.; Ingber, D. E. Microengineered Physiological Biomimicry: Organs-on-Chips. Lab Chip 2012, 12 (12), 2156-2164.

10. Bhatia, S. N.; Ingber, D. E. Microfluidic Organs-on-Chips. Nat. Biotechnol. 2014, 32 (8), 760772.

11. Kawano, A.; Haiduk, C.; Schirmer, K.; Hanner, R.; Lee, L. E. J.; Dixon, B.; Bols, N. C. Development of a Rainbow Trout Intestinal Epithelial Cell Line and its Response to Lipopolysaccharide. Aquacult. Nutr. 2011, 17 (2), E241-E252.

12. Streit, B. Bioaccumulation of Contaminants in Fish. EXS 1998, 86, 353-387.

13. Kelly, B. C.; Gobas, F. A.; McLachlan, M. S. Intestinal Absorption and Biomagnification of Organic Contaminants in Fish, Wildlife, and Humans. Environ. Toxicol. Chem. 2004, 23 (10), 23242336.

14. LeBleu, V. S.; Macdonald, B.; Kalluri, R. Structure and Function of Basement Membranes. Exp. Biol. Med. (Maywood) 2007, 232 (9), 1121-1129.

15. Geppert, M.; Sigg, L.; Schirmer, K. A Novel Two-Compartment Barrier Model for Investigating Nanoparticle Transport in Fish Intestinal Epithelial Cells. Environ. Sci.-Nano 2016, 3 (2), 388-395.

16. Minghetti, M.; Drieschner, C.; Bramaz, N.; Schug, H.; Schirmer, K. A Fish Intestinal Epithelial Barrier Model Established from the Rainbow Trout (Oncorhynchus mykiss) Cell Line, RTgutGC. Cell Biol. Toxicol. 2017, in press.

17. Kenzaoui, B. H.; Vila, M. R.; Miquel, J. M.; Cengelli, F.; Juillerat-Jeanneret, L. Evaluation of Uptake and Transport of Cationic and Anionic Ultrasmall Iron Oxide Nanoparticles by Human Colon Cells. Int. J. Nanomed. 2012, 7, 1275-1286.

18. Huh, D.; Leslie, D. C.; Matthews, B. D.; Fraser, J. P.; Jurek, S.; Hamilton, G. A.; Thorneloe, K. S.; McAlexander, M. A.; Ingber, D. E. A Human Disease Model of Drug Toxicity-Induced Pulmonary Edema in a Lung-on-a-Chip Microdevice. Sci. Transl. Med. 2012, 4 (159), 159 ra147.

19. Huh, D.; Matthews, B. D.; Mammoto, A.; Montoya-Zavala, M.; Hsin, H. Y.; Ingber, D. E. Reconstituting Organ-Level Lung Functions on a Chip. Science 2010, 328 (5986), 1662-1668.

20. Kim, H. J.; Huh, D.; Hamilton, G.; Ingber, D. E. Human Gut-on-a-Chip Inhabited by Microbial Flora that Experiences Intestinal Peristalsis-Like Motions and Flow. Lab Chip 2012, 12 (12), 21652174.

21. Kim, H. J.; Ingber, D. E. Gut-on-a-Chip Microenvironment Induces Human Intestinal Cells to Undergo Villus Differentiation. Integrat. Biol.: Quantitative Biosciences from Nano to Macro 2013, 5 (9), 1130-1140. 
22. Esch, M. B.; Sung, J. H.; Yang, J.; Yu, C.; Yu, J.; March, J. C.; Shuler, M. L. On Chip Porous Polymer Membranes for Integration of Gastrointestinal Tract Epithelium with Microfluidic 'Body-ona-Chip' Devices. Biomed Microdevices 2012, 14 (5), 895-906.

23. Agrawal, A. A.; Nehilla, B. J.; Reisig, K. V.; Gaborski, T. R.; Fang, D. Z.; Striemer, C. C.; Fauchet, P. M.; McGrath, J. L. Porous Nanocrystalline Silicon Membranes as Highly Permeable and Molecularly Thin Substrates for Cell Culture. Biomaterials 2010, 31 (20), 5408-5417.

24. Halamoda Kenzaoui, B.; Angeloni, S.; Overstolz, T.; Niedermann, P.; Chapuis Bernasconi, C.; Liley, M.; Juillerat-Jeanneret, L. Transfer of Ultrasmall Iron Oxide Nanoparticles from Human BrainDerived Endothelial Cells to Human Glioblastoma Cells. ACS Appl. Mater. Interfaces 2013, 5 (9), 35813586.

25. Jud, C.; Ahmed, S.; Muller, L.; Kinnear, C.; Vanhecke, D.; Umehara, Y.; Frey, S.; Liley, M.; Angeloni, S.; Petri-Fink, A.; Rothen-Rutishauser, B. Ultrathin Ceramic Membranes as Scaffolds for Functional Cell Coculture Models on a Biomimetic Scale. Bioresearch Open Acc. 2015, 4 (1), 457-468.

26. Ma, S. H.; Lepak, L. A.; Hussain, R. J.; Shain, W.; Shuler, M. L. An Endothelial and Astrocyte CoCulture Model of the Blood-Brain Barrier Utilizing an Ultra-Thin, Nanofabricated Silicon Nitride Membrane. Lab Chip 2005, 5 (1), 74-85.

27. Harris, S. G.; Shuler, M. L. Growth of Endothelial Cells on Microfabricated Silicon Nitride Membranes for an In Vitro Model of the Blood-Brain Barrier. Biotechnol. Bioproc. E 2003, 8 (4), 246251.

28. Poinern, G. E. J.; Ali, N.; Fawcett, D. Progress in Nano-Engineered Anodic Aluminum Oxide Membrane Development. Materials 2011, 4 (3), 487-526.

29. Brennan, L. M.; Widder, M. W.; Lee, L. E.; van der Schalie, W. H. Long-Term Storage and Impedance-based Water Toxicity Testing Capabilities of Fluidic Biochips Seeded with RTgill-W1 Cells. Toxicol. In Vitro 2012, 26 (5), 736-745.

30. Hubatsch, I.; Ragnarsson, E. G.; Artursson, P. Determination of Drug Permeability and Prediction of Drug Absorption in Caco-2 Monolayers. Nature Protocols 2007, 2 (9), 2111-2119.

31. Tanneberger, K.; Knobel, M.; Busser, F. J. M.; Sinnige, T. L.; Hermens, J. L. M.; Schirmer, K. Predicting Fish Acute Toxicity Using a Fish Gill Cell Line-Based Toxicity Assay. Environ. Sci. Technol. 2013, 47 (2), 1110-1119.

32. Dayeh, V. R.; Schirmer, K.; Bols, N. C. Applying Whole-Water Samples Directly to Fish Cell Cultures in order to Evaluate the Toxicity of Industrial Effluent. Water Res 2002, 36 (15), 3727-3738.

33. Tanneberger, K.; Rico-Rico, A.; Kramer, N. I.; Busser, F. J.; Hermens, J. L.; Schirmer, K. Effects of Solvents and Dosing Procedure on Chemical Toxicity in Cell-Based In Vitro Assays. Environ. Sci. Technol. 2010, 44 (12), 4775-4781.

34. Wu, S. M.; Wildhaber, F.; Vazquez-Mena, O.; Bertsch, A.; Brugger, J.; Renaud, P. Facile Fabrication of Nanofluidic Diode Membranes Using Anodic Aluminium Oxide. Nanoscale 2012, 4 (18), 5718-5723.

35. Vlassiouk, I.; Apel, P. Y.; Dmitriev, S. N.; Healy, K.; Siwy, Z. S. Versatile Ultrathin Nanoporous Silicon Nitride Membranes. Proc. Nat. Acad. Sci. USA 2009, 106 (50), 21039-21044.

36. Hoess, A.; Thormann, A.; Friedmann, A.; Heilmann, A. Self-Supporting Nanoporous Alumina Membranes as Substrates for Hepatic Cell Cultures. J. Biomed. Mater. Res. A 2012, 100A (9), 22302238.

37. Sundell, K.; Jutfelt, F.; Agustsson, T.; Olsen, R. E.; Sandblom, E.; Hansen, T.; Bjornsson, B. T. Intestinal Transport Mechanisms and Plasma Cortisol Levels during Normal and Out-of-Season ParrSmolt Transformation of Atlantic Salmon, Salmo salar. Aquaculture 2003, 222 (1-4), 265-285.

38. Liang, E.; Chessic, K.; Yazdanian, M. Evaluation of an Accelerated Caco-2 cell Permeability Model. J. Pharmacol. Sci. 2000, 89 (3), 336-345.

39. Organization, W. H. Aluminium. In Guidelines for Drinking-Water Quality, 2nd ed., 1998, 6-15. 40. Wilson, R. W., Aluminum. In Homeostasis and Toxicology of Non-Essential Metals, 1st ed.; Inc., E., Ed. 2012, 67-123.

41. Ojo, A. A.; Wood, C. M. In Vitro Analysis of the Bioavailability of Six Metals via the Gastrointestinal Tract of the Rainbow Trout (Oncorhynchus mykiss). Aquat. Toxicol. 2007, 83 (1), 10-23. 


\section{FIGURES}
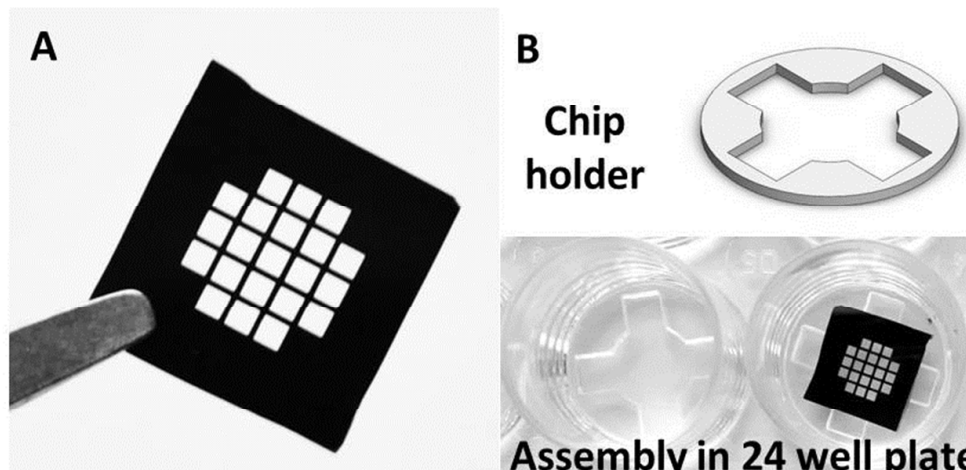

\section{Attachment to insert} holder

\section{Assembly in 24 well plate}

Figure 1. Ultrathin nanoporous alumina supports. (A) Silicon chip (Si-chip) holding 21 square and transparent alumina membranes (chip: $9 \mathrm{~mm}$ x $9 \mathrm{~mm}$ ). (B) One-compartment cell culture set-up: Si-chip is placed on a simple holder within a 24 well plate to allow media supply from both sides of the membrane. (C) Two-compartment permeability set-up: Si-chip is glued onto commercially available 24 well cell culture inserts after PET-membrane removal. 

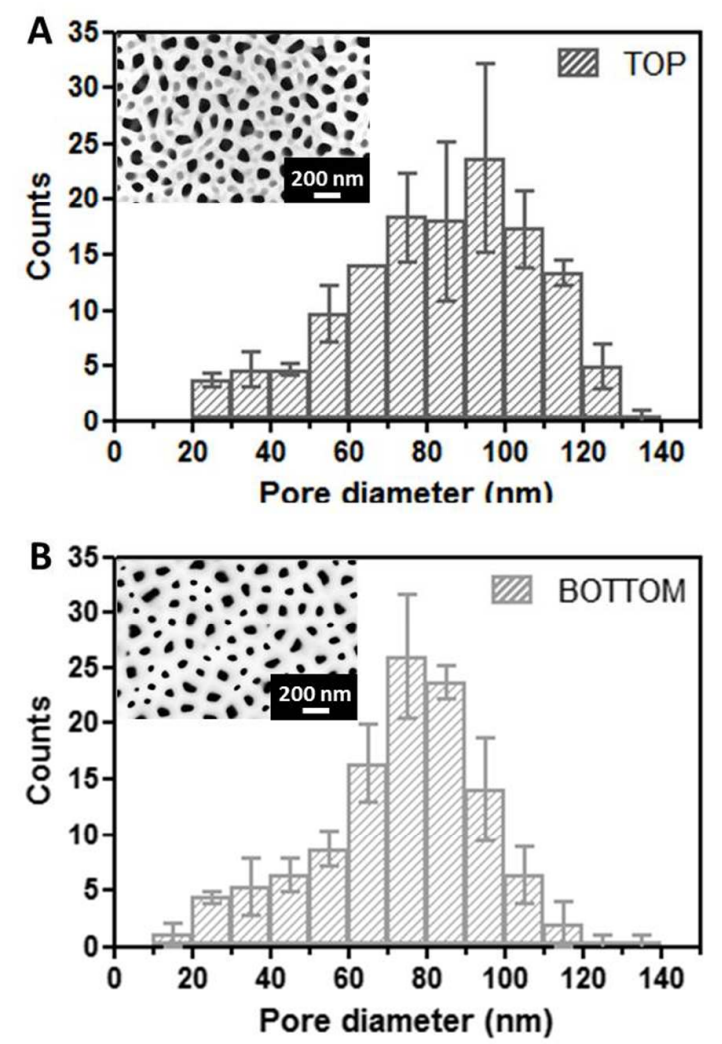

Figure 2. Pore size histograms of alumina membrane from top (A) and bottom side (B). For each histogram, three representative scanning electron microscopy images from independent anodization batches, as depicted in the graph, were analyzed. Shown are the mean values and standard deviation. 
A Start

Equilibrium

$\mathrm{T}=0$

$T=\infty$

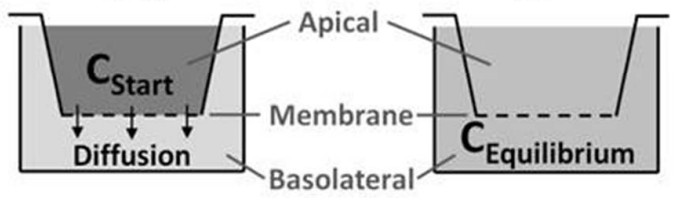

B
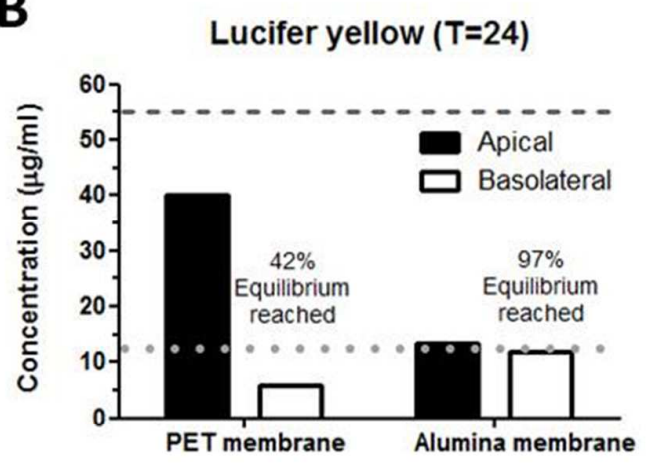

Dextran 40 ( $\mathrm{T}=24)$

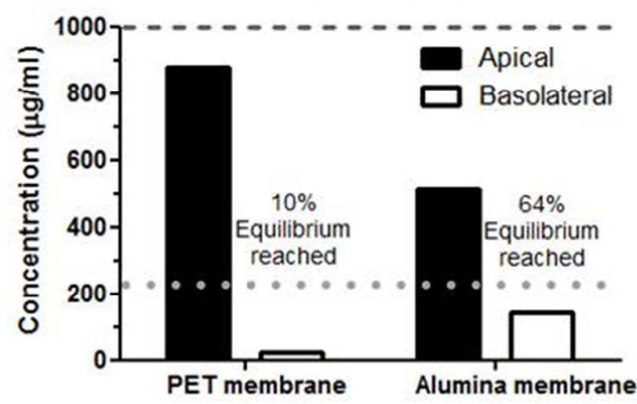

Bovine serum albumin $(\mathrm{T}=24)$

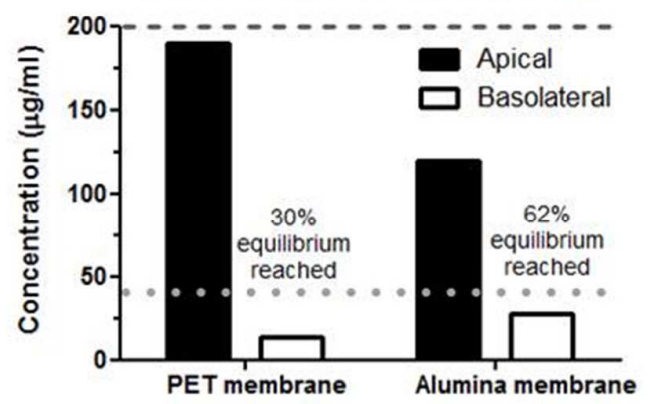

Figure 3. Comparison of membrane permeability between commercial PET and custom made alumina membranes in the absence of cells. (A) Depiction of experimental set-up for both membranes: the apical chamber of the insert system was filled with $400 \mu \mathrm{l}$ of PBS containing either lucifer yellow (LY), starting concentration $\left(\mathrm{C}_{\text {Start }}\right)=55 \mu \mathrm{g} / \mathrm{mL}$; dextran FD40 (FD40), $\mathrm{C}_{\text {Start }}=1000 \mu \mathrm{g} / \mathrm{mL} ;$ or bovine serum albumin (BSA), $\mathrm{C}_{\text {Start }}=200 \mu \mathrm{g} / \mathrm{mL}$. The basolateral chamber was filled with $1.4 \mathrm{~mL}$ of PBS only. The experiment was started at time point 0 hours $(\mathrm{T}=0)$. Over an unknown period of time $(\mathrm{T}=\infty)$ the concentration between the apical and basolateral chamber reached an equilibrium due to diffusion. (B) After 24 hours $(\mathrm{T}=24)$ concentrations of $\mathrm{LY}$, FD40 and BSA were determined in the apical and basolateral chamber and the percentage of reached equilibrium was calculated for the basolateral chamber. The dark grey dashed line indicates $\mathrm{C}_{\text {start }}$ and the light grey dotted line shows predicted $\mathrm{C}_{\text {Equilibrium based on complete diffusion }}$ between apical and basolateral chamber. 
A Top view -24 hours cell culture
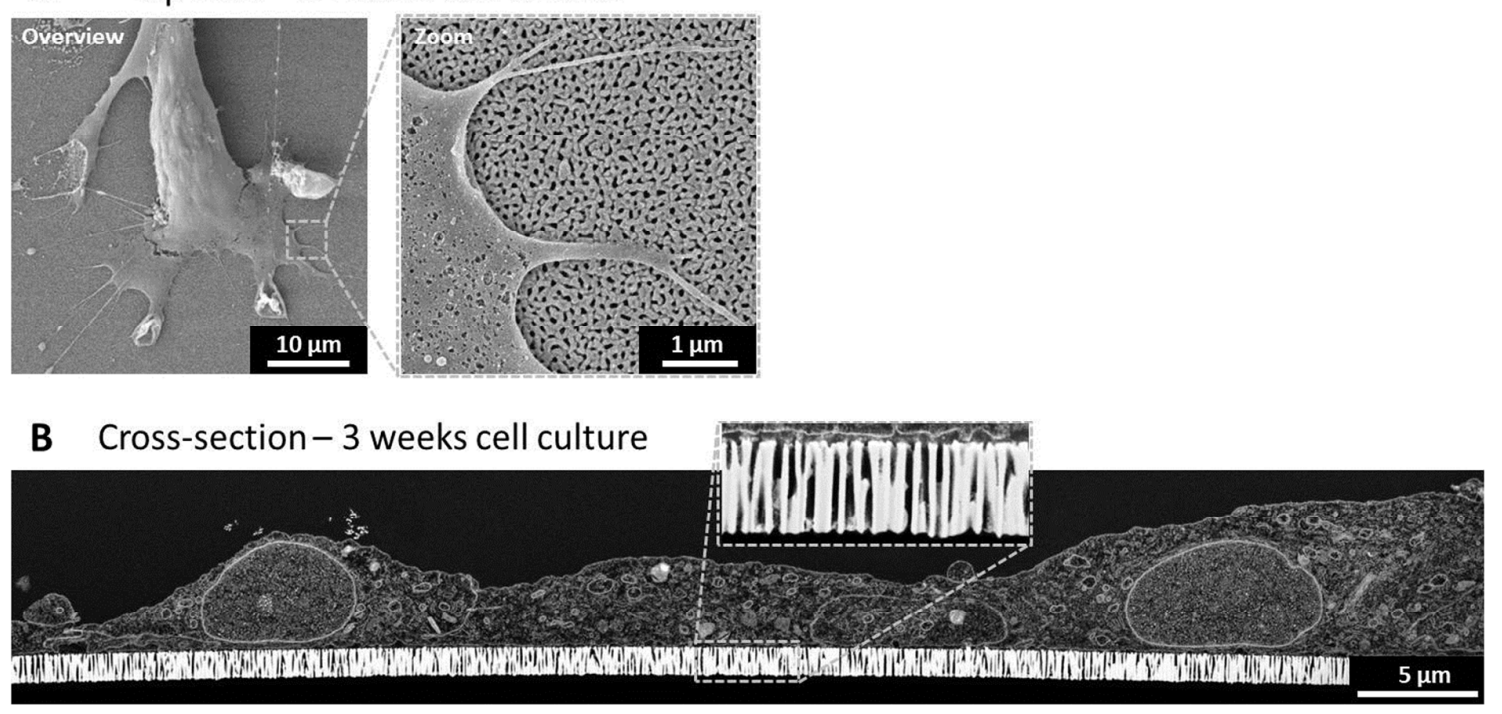

Figure 4. Alumina membranes as cell culture interface for rainbow trout intestinal epithelial cells. (A) Cells were seeded at a low density $\left(20000\right.$ cells $\left./ \mathrm{cm}^{2}\right)$ and cultured for 24 hours prior to scanning electron microscopy. (B) Cells were seeded at a high density (55 000 cells $/ \mathrm{cm}^{2}$ ) and cultured for two weeks. Cross-sections were prepared with focussed-ion-beam and images were taken with transmission electron microscopy. 


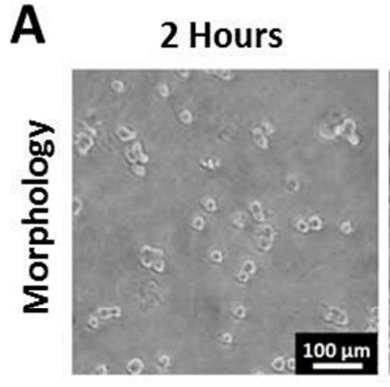

B
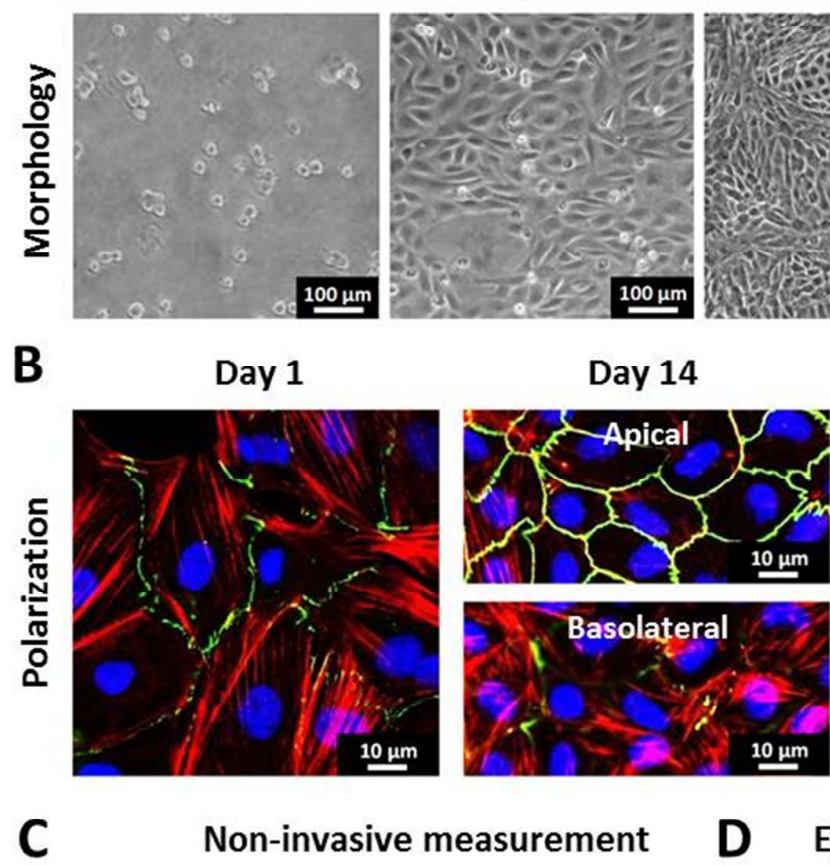

C
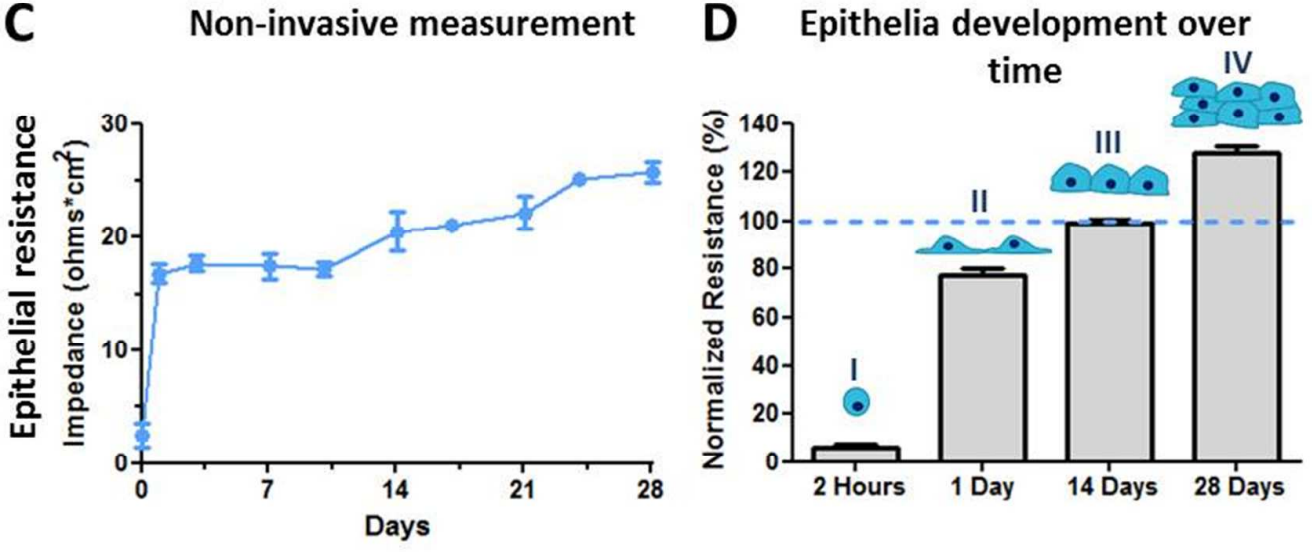

Figure 5. Cell growth, polarization and epithelial resistance of rainbow trout intestinal epithelial cells (RTgutGC) cultured on alumina membranes. (A) Light microscopy of cells cultured for two hours, $1,14 \& 28$ days. (B) Confocal microscopy of cells stained for tight junction protein ZO-1 (green), cytoskeleton f-actin (red) and nuclei (blue). Day 1: Tight junctions and actin stress fibres are found on the same optical plane. Day 14: Tight junctions migrate to the apical cell boarder while actin stress fibres remained basolateral (distance between apical and basolateral images was $4 \mu \mathrm{m}$ ). Cross-section: Assembly of z-stack images (staining for ZO-1 and nucleus) show unpolarised cells at day one, polarized monolayer at day 14 and multilayer formation at day 28. (C \& D) Epithelial resistance was measured using impedance spectroscopy for 28 days at a frequency of $1500 \mathrm{~Hz}$. (C) Ohmic resistance is depicted as function over time. Presented are the means of three biological replicates and 
standard deviation. (D) Resistance values are normalized to day 14, where cells formed a polarized epithelial monolayer. According to culture periods, the epithelial development can be arranged in four stages: Stage I ( 0-5 hours): Cell seeding and attachment; Stage II ( $\sim 5$ hours -3 days): Cell spreading and formation of a confluent monolayer; Stage III ( $\sim 3-$ 21 days): Cell growth and polarization; Stage IV ( $\sim 21-28$ days): Further cell division and multilayer formation. 

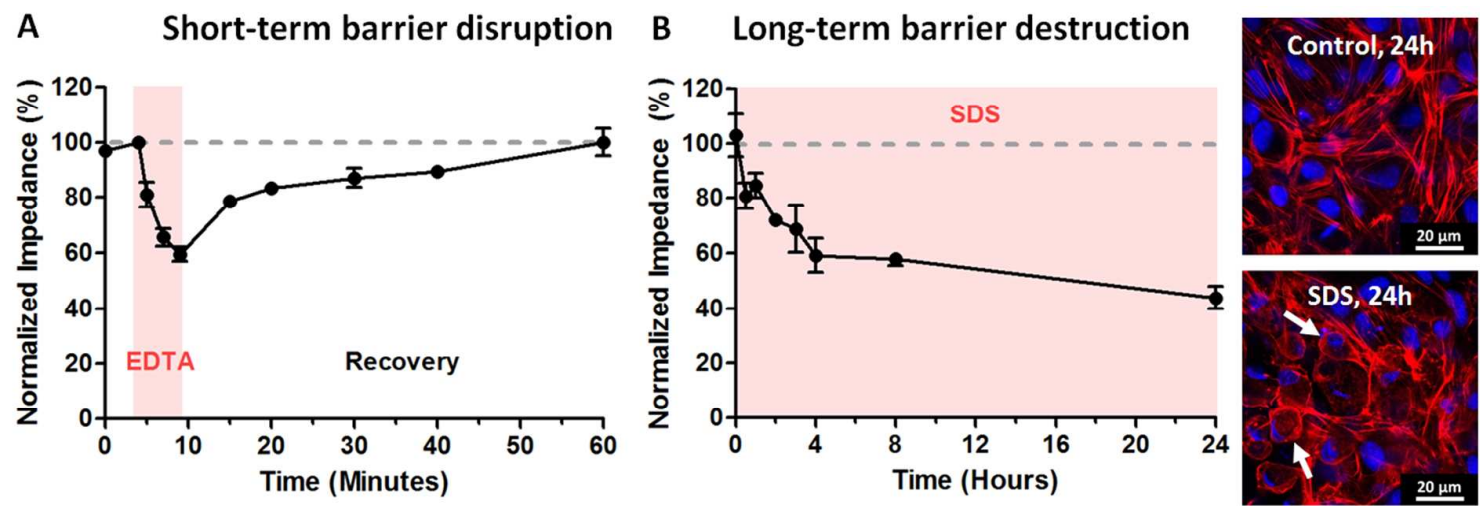

Figure 6. Impedance based toxicity testing on mature epithelia. (A) Normalized impedance during short-term exposure (5 min) to EDTA (Ethylenediaminetetraacedic acid) and subsequent recovery. (B) Long-term exposure (24 hours) to SDS (Sodium dodecyl sulfate). Left: Normalized impedance; Right: Cytoskeletal changes after 24 hours SDS exposure. Immunocytochemical staining of cytoskeleton f-actin (red) and nucleus (blue) revealed a fibre-like network of f-actin in untreated samples (control) and less organized f-actin fibres, dominantly present at the cell periphery, in SDS exposed samples. Normalized impedance of (A) \& (B): Presented are the means of at least three biological replicates and standard deviation. Each value was normalized to control. Coloured area indicates chemical exposure period. 


\section{A Al release into cell culture medium B Atomic layer deposition with $\mathrm{TiO}_{2}$}
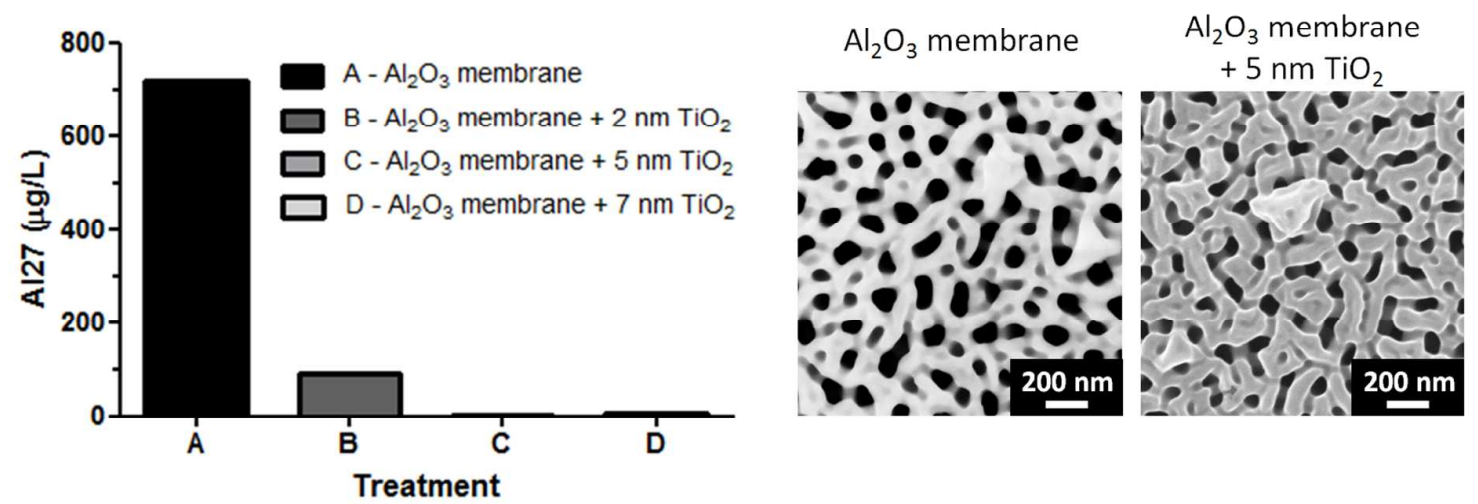

Figure 7. Al release from membranes and prevention. (A) Al concentrations found in cell culture medium after incubation with alumina membranes for seven days at $19^{\circ} \mathrm{C}(1$ $\mathrm{mL} /$ chip). Tested were untreated membranes $\left(\mathrm{Al}_{2} \mathrm{O}_{3}\right)$ and membranes with an atomic layer deposition (ALD) of different $\mathrm{TiO}_{2}$ thicknesses $(2,5 \& 7 \mathrm{~nm})$. (B) Changes in membrane morphology before and after ALD with $5 \mathrm{~nm} \mathrm{TiO}_{2}$. 


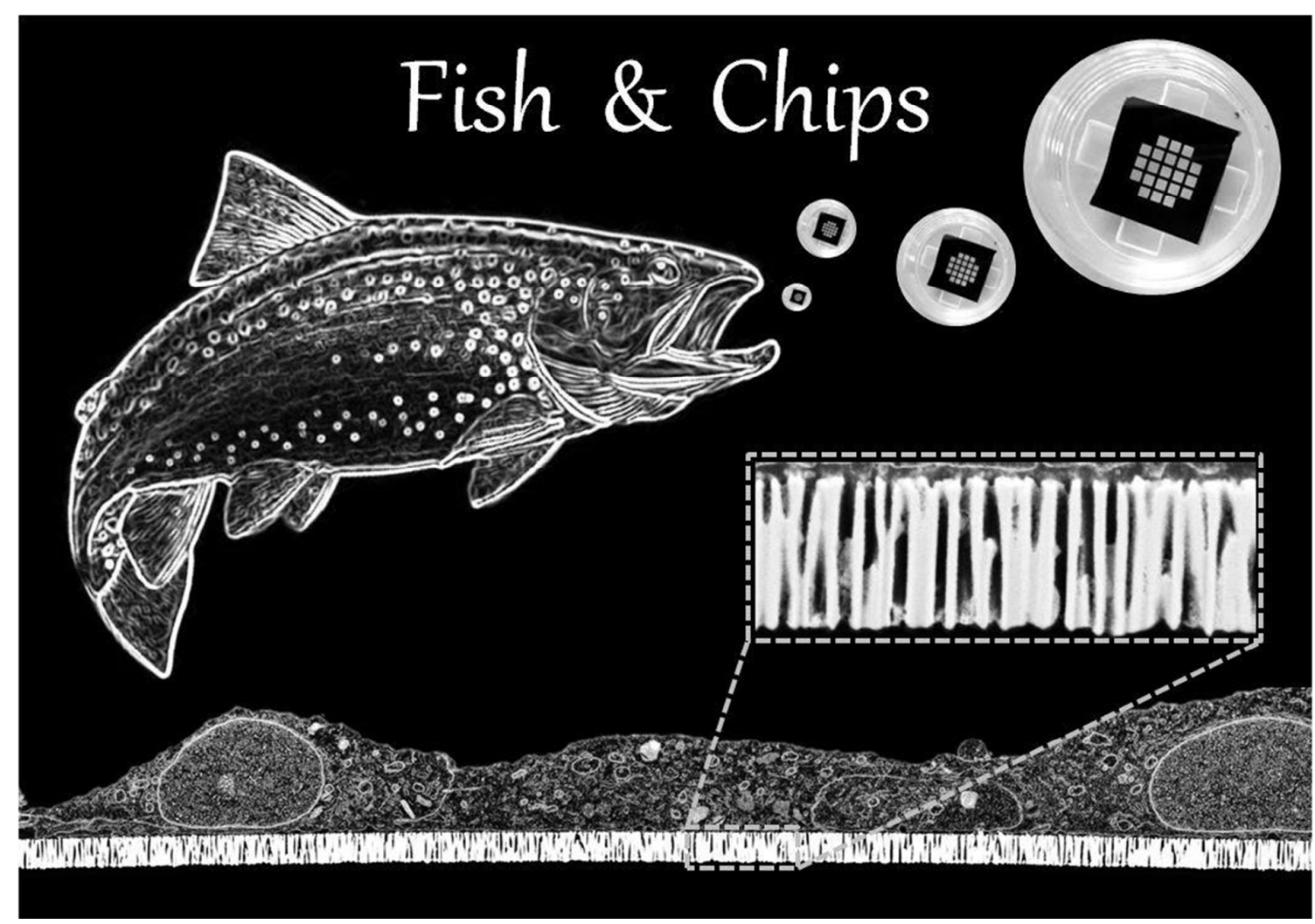

Graphical Abstract 